\title{
Long term outcome of ocular adnexal lymphoma subtyped according to the REAL classification
}

\author{
C Auw-Haedrich, S E Coupland, A Kapp, A Schmitt-Gräff, R Buchen, H Witschel
}

\begin{abstract}
Aim-To classify ocular adnexal lymphomas according to the Revised European and American Lymphoma (REAL) classification and to determine any correlation between clinical features or histomorphological variables with the patients' outcome.

Methods-Conventional and immunohistology were performed on representative sections of 53 specimens of 46 patients with ocular adnexal lymphoma. The antibodies used were CD20, BCL-2, CD21, CD23, CD43, CD3, CD5, p53, cyclin D1, pan-cytokeratin, kappa, lambda, IgD, and IgM. The growth fraction of the tumours was determined using the MIB-1 antibody directed against the Ki-67 antigen. Clinical follow up data regarding the outcome were obtained from the treating physicians and/or hospital files. The Student's $t$ test and log rank test were used for statistical analysis.
\end{abstract}

Results-The patient collective consisted of 29 females and 17 males with an age range of 32-89.7 years (average 63 years). Almost all specimens represented $B$ cell non-Hodgkin's lymphomas: extranodal marginal zone lymphoma $(\mathrm{EMZL})(\mathrm{n}=38)$, diffuse large cell $B$ cell lymphoma $(n=8)$, lymphoplasmocytic lymphoma/immunocytoma $(n=2)$, mantle cell lymphoma $(n=2)$, follicle centre lymphoma $(n=1)$, and plasmacytoma $(n=1)$. One case of a secondary anaplastic large cell lymphoma of $T$ cell type (T-ALCL) was diagnosed. The majority of the patients had stage I disease. A variety of therapeutic regimens was administered, the main form of treatment being radiotherapy. The average follow up time was 85 months. Complete remission was achieved in 24 patients (10 after excision alone, eight after radiotherapy alone, three after combined excision and radiotherapy, one after chemotherapy alone, and two after combined radiotherapy and chemotherapy). 12 patients died of causes related to lymphoma; in one patient the cause of death was unknown. Six patients had persistent tumour at final follow up and two patients were lost to follow up. The stage at presentation, as well as the lymphoma malignancy category, had a significant correlation with the final course of the disease $(p=0.0001$ and $p=0.03$, respectively). A significant correlation was also noted between the final outcome $(p<0.05)$ and tumour cell expression for Ki-67 antigen and $\mathrm{p} 53$ protein.

Conclusion- $67 \%$ of patients with ocular adnexal lymphoma had EMZL. The stage at presentation had a significant influence on the final outcome. MIB-1 and p53 expression by the tumour cells proved to be important immunohistochemical markers concerning the prognosis. It is suggested that, following thorough staging investigations, primary EMZL (stage I) (if accessible) should be treated with excisional biopsy and subsequent low dose radiotherapy. Primary diffuse large cell B cell lymphoma of the ocular adnexa requires at least similar therapeutic measures and regular intensive follow up. (Br f Ophthalmol 2001;85:63-69)

Ocular adnexal lymphomas (OAL) represent lymphatic neoplasms which develop as primary or secondary tumour manifestations in the conjunctiva, lid, orbit, lacrimal gland, or lacrimal sac. Most patients with OAL present with localised disease (stage I) in the 6 th or 7 th decade of life. ${ }^{1}$

Many OAL were previously known in the literature as "benign lymphoma" or "pseudolymphomas", as most do contain small monomorphic lymphatic infiltrates similar to reactive lymphoid hyperplasia (RLH) and have a favourable course. ${ }^{2}$ The criteria previously used to distinguish between small cell lymphoma and RLH were not clearly defined and were based mainly on cellular morphology. It was only with the advent of immunohistochemistry and molecular biological studies, such as polymerase chain reaction, together with the recognition of the mucosa associated lymphatic tissue (MALT) lymphoma as an entity in 1983 by Isaacson and Wright, ${ }^{3}$ that the distinction between the two entities became clearer.

Previous studies ${ }^{145}$ have classified OAL using the European Kiel classification ${ }^{6}$ and the American "working formulation". ${ }^{7}$ More recent studies have applied the Revised European American Lymphoma (REAL) classification, which is probably more appropriate owing to its inclusion of both nodal and extranodal lymphomas. The REAL classification subdivides lymphomas on the basis of histological, immunophenotypic, and genetic features. ${ }^{8}$ It includes elements of both the European Kiel classification ${ }^{9}$ and the American "working formulation". According to the REAL classification, the most common subtype of lymphoma in the ocular adnexa is the extranodal marginal zone B cell lymphoma (EMZL). ${ }^{20}$ The term EMZL was proposed by 
the REAL classification to incorporate MALT lymphomas with or without a mucosa, as it since had become apparent that they can also occur in locations where neither a mucosa nor an epithelium is present, such as the orbit. In total, EMZL comprise together approximately $10-33 \%$ of all lymphomas. ${ }^{11}$

Few investigations have been undertaken to address the long term outcome of OAL classified according to the REAL classification. ${ }^{2} 1012$ Recent studies revealed a significant correlation between clinical features and immunohistochemical markers with the long term outcome of OAL, ${ }^{10}$ whereas earlier ${ }^{5}$ and also recent studies ${ }^{12}$ have not. The aim of the current study was to reclassify OAL on file in the University Eye Hospital Freiburg according to the REAL classification and to correlate the tumour location, stage at presentation, lymphoma malignancy category, as well as tumour cell positivity for p53 and MIB-1 expression with the clinical outcome.

\section{Material and methods}

The archives of the eye pathology department of Freiburg were reviewed for lymphoproliferative lesions of the ocular adnexa. The paraffin blocks, containing formalin fixed specimens which were collected within the time period April 1976 to September 1998, were obtained and sections thereof stained with haematoxylin and eosin, periodic acid Schiff, and Giemsa. For immunohistochemistry an antigen retrieval method using pressure cooker or microwave was performed before immunohistochemical staining. ${ }^{13}$ The following monoclonal antibodies were used at the first stage incubation: CD20 (clone L26), CD21 (clone 1F8), CD43 (clone DF-T1), BCL protein 2 (clone 124), VS38c, p53 (clone DO-7), pancytokeratin marker MNF116 from Dako (Glostrup, Denmark), CD5 (clone UCHT2), Ki-67 antigen, cyclin D1 (clone G124-326) from Pharmingen (San Diego, CA, USA), and CD23 (clone 1B12) from Novocastra (Newcastle upon Tyne, UK). Polyclonal antibodies were used to examine the positivity for CD3 antigen and the immunoglobulin chains kappa, lambda, IgM, and IgD (Dako). The PAP method was used for the demonstration of immunoglobulin (Ig) molecule light chains kappa and lambda (Dako), heavy chains IgM and $\operatorname{IgD}$ (Dako), as well as the human p53 protein (Dako) and the APAAP method ${ }^{14}$ for the other antibodies. Based on the morphological features and immunophenotype, the lesions were subtyped according to the REAL classification $^{8}$ by two of us (SEC and ASG) without knowledge of the previous diagnosis or of the clinical outcome. The number of MIB-1 and p53 protein positive cells was determined by counting the number of cells with nuclear positivity for these markers per $5 \times 100$ tumour cells using the $40 \times$ objective.

With regard to the patients' outcome, information was either obtained from the clinical files or contact was made with the patients' ophthalmologist or general practitioner. Clinical staging of the lymphomas was undertaken according to Ann Arbor classification. ${ }^{15}$ Staging investiga- tions included $x$ ray examination, abdominal sonography, and bone marrow biopsy or computed tomograph scans and bone marrow biopsy, depending on the date of presentation. Stage I disease included both unilateral or bilateral ocular adnexal lesions without evidence of nodal involvement. "Primary disease" was defined as primary involvement of the ocular adnexa. "Secondary disease" was defined as a lymphomatous infiltration of the ocular adnexa by an identical lymphoma of another primary site. "Stage at presentation" was defined as the stage of disease at the time of manifestation in the ocular adnexa.

For statistical analysis, the lymphomas were divided into two categories, "low" and "high" grade malignancy as described previously. ${ }^{10}$ "Low grade" malignant lymphomas included extranodal marginal zone lymphoma, lymphoplasmocytic lymphoma/immunocytoma, mantle cell lymphoma, plasmacytoma, and follicle centre lymphoma (grade 1 and 2). "High grade" malignant lymphomas included diffuse large cell B cell lymphoma and systemic T cell lymphoma. Only these two larger groups were analysed since most of the subtypes contained too few cases for statistical analysis. Using the Student's $t$ test, $\chi^{2}$ two tailed test, and log rank test, the following factors were analysed: course of disease, stage at presentation, stage at final follow up, the tumour location, the lymphoma subtype, Ki-67 antigen, and p53 positivity. Actuarial survival curves were plotted using the Kaplan-Meier method. ${ }^{16}$

\section{Results}

A review of the archives revealed 53 OAL of 46 patients with an age range of $32-89$ years, the average age being 63 years. The patient collective consisted of 29 females and 17 males. The average follow up time was 84.7 months (range 2.4-239 months; median 61 months). The OAL occurred in the orbit $(n=22)$, lid $(n=11)$, conjunctiva $(n=18)$, lacrimal sac $(n=1)$, and sclera $(n=1)$. Lymphoproliferative lesions of the ocular adnexa with morphological and immunohistological criteria of RLH were excluded from the study.

\section{HISTOLOGICAL RESULTS}

The various subtypes of lymphoma were diagnosed and their location and the extent of disease are summarised in Table 1 . The most common lymphoma was the EMZL, occurring in 38 specimens of 31 patients. Histologically, these tumours showed numerous secondary follicles with a broadening of the marginal zone by small centrocyte-like cells with occasional intermingled blasts. Frequently, the tumour cells displayed a plasmacellular differentiation and infiltrated reactive follicle centres (Fig 1A and B) or adjacent epithelium with the formation of lymphoepithelial lesions (Fig 1C). Ten of these 38 EMZL were previously diagnosed as RLH, seven as lymphoplasmocytoid immunocytoma, four as centroblastic centrocytic B cell lymphoma (the REAL equivalent being follicle centre lymphoma), and five as "low grade malignant B cell lymphoma". The remaining specimens had been initially diag- 
Table 1 Histopathological diagnoses according to the REAL classification, location, and manifestation

\begin{tabular}{|c|c|c|c|c|c|c|c|c|c|c|}
\hline \multirow[b]{2}{*}{ Diagnosis } & \multicolumn{5}{|l|}{ Location } & \multirow[b]{2}{*}{$\begin{array}{l}\text { Total (no of } \\
\text { patients) }\end{array}$} & \multicolumn{4}{|c|}{ Manifestation } \\
\hline & $\begin{array}{l}\text { Total (no of } \\
\text { specimens) }\end{array}$ & Orbit & Conjunctiva & Lid & Others & & Primary & $\begin{array}{l}\text { Primary, } \\
\text { later systemic } \\
\text { involvement }\end{array}$ & Secondary & Unclear \\
\hline EMZL & 38 & 16 & 15 & 7 & 0 & 31 & 18 & 6 & 5 & $2^{\star}$ \\
\hline DLCL & 8 & 4 & 2 & 1 & 1 & 8 & 3 & 3 & 1 & $1^{\star}$ \\
\hline FCL & 1 & 1 & 0 & 0 & 0 & 1 & 0 & 0 & 1 & 0 \\
\hline MCL & 2 & 0 & 1 & 1 & 0 & 2 & 0 & 1 & 1 & 0 \\
\hline PCT & 1 & 0 & 0 & 0 & 1 & 1 & 1 & 0 & 0 & 0 \\
\hline LPCI & 2 & 1 & 0 & 1 & 0 & 2 & 1 & 0 & 1 & 0 \\
\hline STL & 1 & 0 & 0 & 1 & 0 & 1 & 0 & 0 & 1 & 0 \\
\hline
\end{tabular}

^EMZL or DCLC with primary manifestation, the outcome was not known.

nosed as EMZL according to the REAL Classification. In all cases, a monotypical expression of immunoglobulin light chains in the cell cytoplasm or on the cell membrane was found, confirming the diagnosis of lymphoma versus RLH.

The second most common lymphoma subtype in this series was the diffuse large cell B cell lymphoma (DLCL), which was diagnosed in eight specimens of eight patients $(17 \%$ of the total, Table 1). These tumours were characterised by a diffuse proliferation of medium to large sized atypical lymphoid cells with large nuclei, prominent sometimes multiple nucleoli and numerous atypical mitotic figures (Fig 1D).

Of the remaining specimens, two were classified as lymphoplasmacytic lymphoma/ immunocytoma (Fig 1E), two as mantle cell lymphoma (Fig $1 \mathrm{~F}$ ), one scleral specimen as plasmacytoma (Fig 1G), one as follicle centre lymphoma (grade 1), and another as a lid manifestation of a systemic anaplastic large cell lymphoma of $\mathrm{T}$ cell type, T-ALCL. The morphological and immunohistochemical features of the latter case have been described elsewhere. ${ }^{17}$

TUMOUR MANIFESTATION AND LOCATION

A primary lymphoma manifestation was observed in 27 of 37 patients with "low grade malignant" category lymphomas (73\%) and in seven of nine patients with the "high grade malignant" category lymphomas $(78 \%)$. The primary lymphomas occurred in the orbit in 17 specimens, in the conjunctiva in 13 , in the lid in eight, and in the sclera in one. Ten patients ( $22 \%$ of all patients) had a secondary manifestation: four in the orbit, three in the conjunctiva, three in the lid (Table 1).

STAGE AT PRESENTATION

Most patients had stage IE at initial presentation: $81 \%$ with low grade malignant category lymphomas and $67 \%$ with high grade malignant category lymphomas (Table 2). No significant correlation was found between the lymphoma category of malignancy and the stage at initial manifestation in the ocular adnexa $(\mathrm{p}=0.5)$.

TREATMENT, STAGE AT FINAL FOLLOW UP, AND CLINICAL OUTCOME

Different therapeutic regimens were appliedexcision, radiotherapy, chemotherapy, and various combinations of these. The dosage of radiotherapy varied between 4 and $50 \mathrm{~Gy}$; the most common chemotherapeutics used included cyclophosphamide, vincristine and prednisone. The stage at final follow up and the treatment modality applied are shown in Table 2. While 19 of 31 patients (59\%) with an EMZL achieved complete remission after therapy, 10 had persistent tumour in the following clinical stages: stage I $(n=2)$, stage III $(\mathrm{n}=3)$, and stage IV $(\mathrm{n}=5)$. In two patients the stage at final follow up was not known. Interestingly, one female patient with a bilateral orbital EMZL, who had been treated with radiotherapy, developed a DLCL of the conjunctiva 7 years later.

Complete remission was achieved in only two of six patients (33\%) with non-EMZL low grade malignant lymphomas. Persistent tumour was seen in three patients with non-EMZL low grade malignant lymphomas, two of whom notably had mantle cell lymphoma. Complete remission was achieved in eight patients, whose specimens were previously diagnosed as $\mathrm{RLH}$, after treatment in the form of surgical excision $(n=7)$ and radiotherapy $(n=1)$. Two patients, however, had recurrences before complete remission was achieved. Three of nine patients $(33 \%)$ with a high grade malignant lymphoma achieved complete remission; however, five others (56\%) had stage IV at final follow up; in one patient the stage was unclear.

Complete remission was achieved, therefore, in 24 of the original 46 patients $(52 \%)$ and persistent tumour was seen in 18 patients (39\%) after an average follow up period of 85 months. Five patients, in whom a complete remission had been initially achieved, died of causes unrelated to their lymphoma. Six patients with persistent tumour at final follow up were still alive at the time of our investigation (stage I: $n=2$, stage III: $n=3$, stage IV: $n=1), 12$ patients died of lymphoma related causes (EMZL, five patients; lymphoplasmacytic lymphoma/immunocytoma, one; mantle cell lymphoma, one; diffuse large cell $\mathrm{B}$ cell lymphoma, four; and systemic $\mathrm{T}$ cell lymphoma, one) (Table 2). Ten of the 36 patients $(27 \%)$ with a primary manifestation developed systemic involvement after 95 months on average.

CORRELATION BETWEEN LYMPHOMA MALIGNANCY CATEGORIES, CLINICAL SIGNS, AND THE CLINICAL ouTCOME

The stage at initial manifestation, as well as the lymphoma malignancy category, showed a sig- 
nificant correlation with the final course $(p=0.0001$ and $p=0.03$, respectively, Fig 2 and 3). Although statistically not significant, a difference in the course of the ocular adnexal lymphomas was noted depending on their location $(p=0.4)$. Complete remission was achieved in $45 \%$ of the orbital cases, in $39 \%$ of the conjunctival cases, and in $18 \%$ of the lid lymphomas. Death related to lymphoma was the final course in $14 \%, 22 \%$, and $36 \%$ of patients with lymphomas located at the orbit, conjunctiva, and lid, respectively (Table 3).
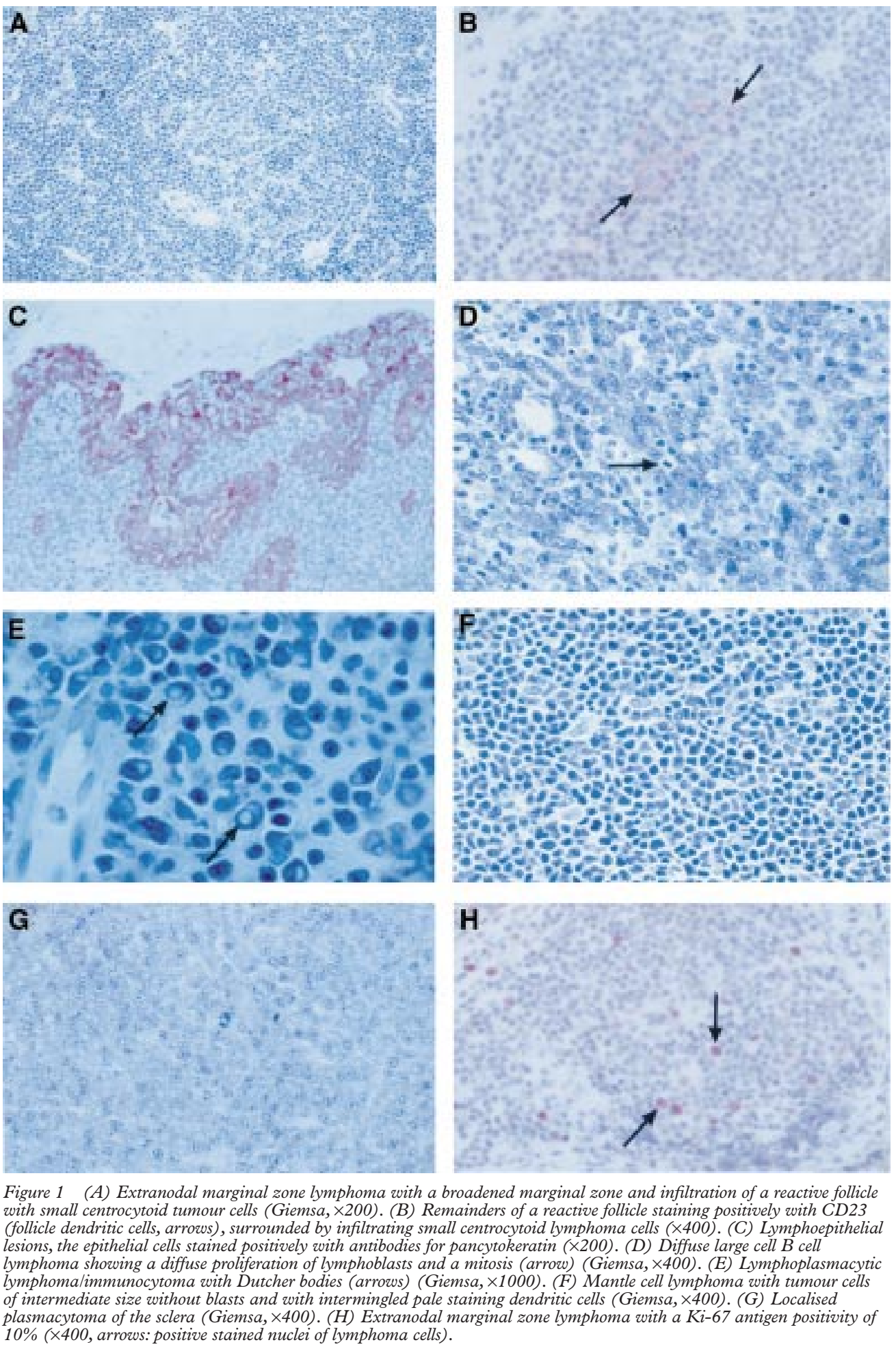

Figure 1 (A) Extranodal marginal zone lymphoma with a broadened marginal zone and infiltration of a reactive follicle with small centrocytoid tumour cells (Giemsa, $\times 200)$. (B) Remainders of a reactive follicle staining positively with CD23 (follicle dendritic cells, arrows), surrounded by infiltrating small centrocytoid lymphoma cells $(\times 400)$. (C) Lymphoepithelial lesions, the epithelial cells stained positively with antibodies for pancytokeratin (×200). (D) Diffuse large cell B cell lymphoma showing a diffuse proliferation of lymphoblasts and a mitosis (arrow) (Giemsa, $\times 400)$. (E) Lymphoplasmacytic lymphoma/immunocytoma with Dutcher bodies (arrows) (Giemsa, $\times 1000$ ). (F) Mantle cell lymphoma with tumour cells of intermediate size without blasts and with intermingled pale staining dendritic cells (Giemsa, $\times 400)$. (G) Localised plasmacytoma of the sclera (Giemsa, $\times 400$ ). (H) Extranodal marginal zone lymphoma with a Ki-67 antigen positivity of $10 \%$ ( $\times 400$, arrows: positive stained nuclei of lymphoma cells).

CORRELATION BETWEEN THE POSITIVITY OF IMMUNOHISTOCHEMICAL MARKERS AND THE

percentage of $\mathrm{Ki}-67$ antigen expression correlated significantly with the final outcome (p<0.05). Lymphomas of the low grade maligantigen positivity of $5 \%$ (range $0-20 \%$ ) (Fig $1 \mathrm{H})$, whereas those of the high grade maligcategory had an average Ki-67 antigen ence between both groups is statistically
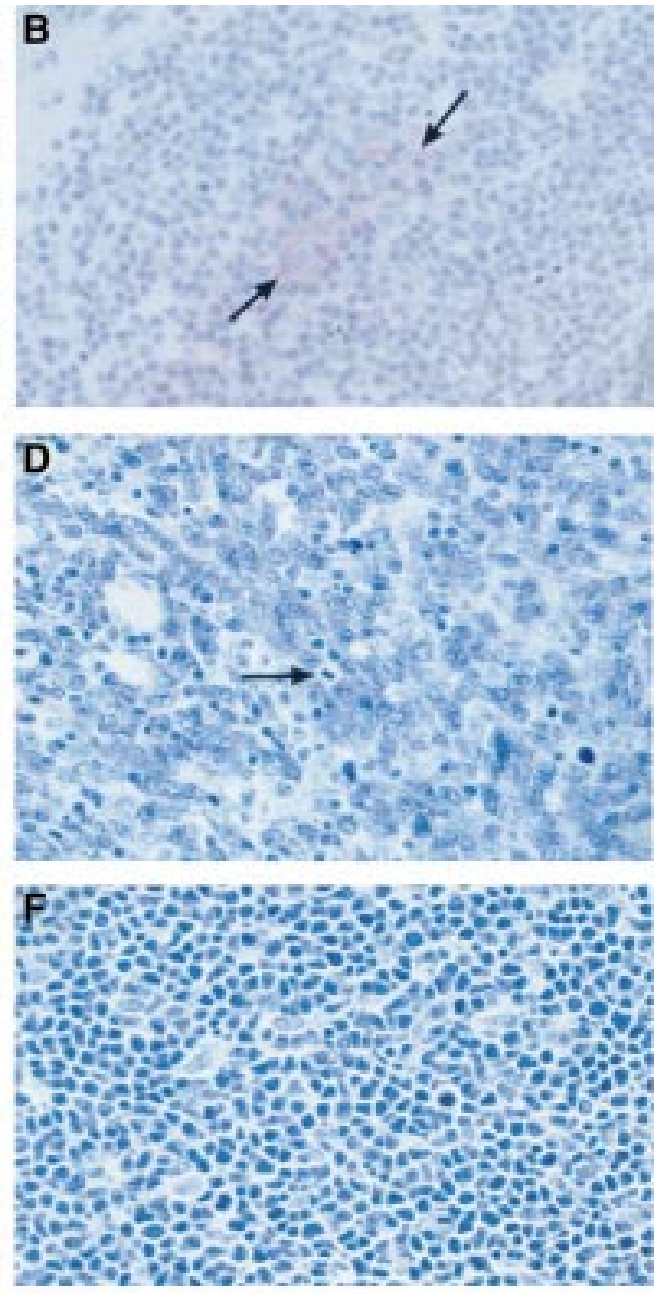
Table 2 Stage at diagnosis and stage at final follow up, depending on treatment (number of patients)

\begin{tabular}{|c|c|c|c|c|c|c|c|c|c|c|}
\hline & \multicolumn{4}{|c|}{ Stage at diagnosis } & \multicolumn{6}{|l|}{ Stage at final follow up } \\
\hline & Stage I & Stage II & Stage III & Stage IV & Complete remission & Stage I & Stage II & Stage III & Stage IV & Unclear \\
\hline EMZL & 26 & 1 & 1 & 3 & $8 \mathrm{E}, 5 \mathrm{R}, 1 \mathrm{C}, 3 \mathrm{ER}^{\star}, 2 \mathrm{RC}$ & $\begin{array}{l}1 \mathrm{R} \\
1 \mathrm{ER}^{\star}\end{array}$ & & 1E, $1 \mathrm{C}, 1 \mathrm{RC}$ & $\mathbf{1 E}, \mathbf{1 C}, 1 \mathrm{C}, \mathbf{2 R C}$ & $2 \mathrm{RC}$ \\
\hline $\begin{array}{l}\text { Other low grade } \\
\text { malignancy (incl MCL) }\end{array}$ & 4 & 1 & 1 & $\begin{array}{l}0 \\
0\end{array}$ & $1 \mathrm{E}, 1 \mathrm{R}$ & & & $1 \mathrm{~F}$ & 1C & $1 \mathrm{ER}$ \\
\hline $\begin{array}{l}\text { MCL } \\
\text { High grade malignancy }\end{array}$ & $\begin{array}{l}1 \\
6\end{array}$ & $\begin{array}{l}0 \\
0\end{array}$ & $\begin{array}{l}1 \\
1\end{array}$ & 2 & $1 \mathrm{E}, 2 \mathrm{R}$ & & & & 1R, 3C, 1RC & $1 \mathrm{R}$ \\
\hline Total & 36 & 2 & 3 & 5 & & & & & & \\
\hline
\end{tabular}

${ }^{\star}$ In one case two recurrences after excision alone, complete remission/stage I following radiotherapy. $\mathrm{E}=$ excision, $\mathrm{R}=$ radiotherapy, $\mathrm{C}=$ chemotherapy; bold numbers $=$ patients whose death was related to lymphoma.

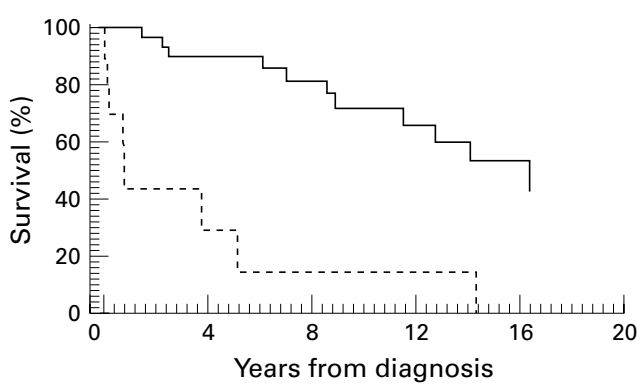

Figure 2 Kaplan-Meier curve. Stage of disease at time of presentation related to the survival (solid line, stage I; broken line, stage II-IV; log rank test: $p=0.0001)$.

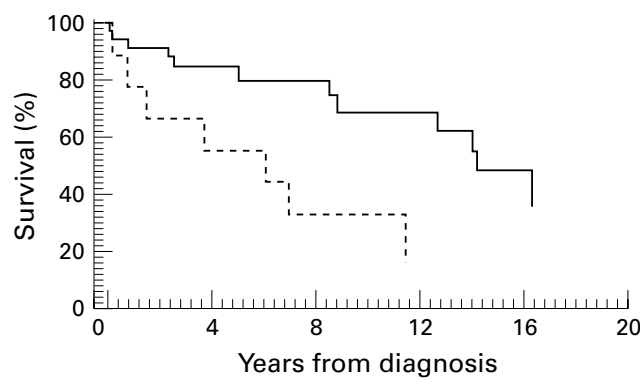

Figure 3 Kaplan-Meier curve. Lymphoma category of malignancy related to survival (solid line, low grade; broken line, high grade; log rank test: $p=0.03$ ).

significant $(p<0.001)$. Similarly, the tumour cell p53 protein expression demonstrated a significant correlation with the final course $(\mathrm{p}<0.05)$. The average percentage of $\mathrm{p} 53$ positivity was $5 \%$ (range $0-15 \%$ ) in the lymphomas of the low grade malignant category and $37 \%$ (range 15-70\%) in those of the "high grade" malignant category $(p<0.001)$. Although tumour cells in five EMZL from four patients expressed the CD5 antigen, this marker did not prove to be prognostically significant.

\section{Discussion}

Similar to other series, ${ }^{2}{ }^{10} 18$ the most common lymphoma subtype in our collection of ocular adnexal lymphomas was the EMZL (67\% of our patients). Approximately one third of these

Table 3 Location of tumour and outcome

\begin{tabular}{llll}
\hline & Orbit (22) & Conjunctiva (18) & Lid (11) \\
\hline Complete remission & $\mathbf{1 0}(\mathbf{4 5 \%})$ & $\mathbf{7}(\mathbf{3 9 \%})$ & $\mathbf{2}(\mathbf{1 8 \%})$ \\
Persistent tumour & $3(14 \%)$ & $2(11 \%)$ & $1(9 \%)$ \\
Recurrence & $1(5 \%)$ & $3(17 \%)$ & $1(9 \%)$ \\
Death related to lymphoma & $\mathbf{3 ( 1 4 \% )}$ & $4(\mathbf{2 2 \%})$ & $\mathbf{4}(\mathbf{3 2 \%})$ \\
Death not related to lymphoma & $2(9 \%)$ & $1(6 \%)$ & $3(27 \%)$ \\
Lost to follow up & $2(9 \%)$ & $1(6 \%)$ & 0 \\
Death of unknown cause & $1(5 \%)$ & 0 & 0
\end{tabular}

Note: The two remaining tumours of the 53 specimen were located in the lacrimal sac and sclera. cases had been previously diagnosed as RLH. A revision of the original diagnosis could be made, however, on the basis of the morphology and the immunophenotype of the infiltrating cells, in particular, the demonstration of a monotypical expression of either the light or heavy chains of the immunoglobulin molecules. This relatively high proportion of lymphoma cases with the former diagnosis RLH exemplifies the difficulty in distinguishing RLH and many EMZL on the basis of conventional histology. EMZL was only described as an entity in 1983 by Isaacson and coworkers, and, therefore, it can be assumed that many EMZL of the ocular adnexa (and other sites) were misdiagnosed as RLH before this description. It would also explain the relatively high incidence of reported progression of RLH of the ocular adnexa into systemic lymphoma $(15-29 \%)$ described in the literature. ${ }^{19}{ }^{20} \mathrm{De}-$ spite the original "misdiagnosis" of RLH in 10 specimen of eight patients in the current series, the patients were either treated with radiotherapy or complete excision, whereby complete remission was achieved. Although a recurrence occurred in two patients, systemic disease was not observed over a follow up period of 172 months, which is significantly longer than the average follow up time of all patients (85 months).

Of the patients with an EMZL of the ocular adnexa, $84 \%$ had primary disease and $16 \%$ a secondary lymphomatous manifestation. Similar data were obtained in two previous larger studies. $^{210}$ The EMZL occurred with equal frequency in the orbit and conjunctiva (40\%), but less frequently in the lid $(20 \%)$. Although almost identical results were published by other authors, ${ }^{2-10} 18$ this distribution is surprising considering that, in contrast to the conjunctiva, orbital soft tissue does not contain any intrinsic lymphoid tissue. ${ }^{21}$

The second most common lymphoma subtype in the current series was the DLCL, different from an investigation of 99 OAL previously conducted by one of us, ${ }^{10}$ which demonstrated follicle centre lymphoma as being the second most common subtype (10 cases), followed by DLCL (nine cases). Combination of the two separate lymphoma collections, however, confirms DLCL as being second in frequency in these tissues. A further difference between these two studies was the finding by Coupland et al, that DLCL of the ocular adnexa occurred only in patients with lymphomatous disease stage II or above. ${ }^{10}$ In the current study, six of the eight patients with 
DLCL of the ocular adnexa presented initially with stage I disease. Two of these patients later developed systemic disease, despite radiotherapy and, in one patient, adjuvant chemotherapy. The discrepancies between the two investigations could possibly be explained by the near majority of the DLCL occurring in the orbit in the earlier series, resulting in relatively late presentation in some cases. Further, one patient was proved to be HIV positive and this lymphoma showed a particularly aggressive course. ${ }^{10}$ The findings of the present series are comparable, however, to those of White et $a l_{,}^{2}$ who reported six of seven patients with DLCL with stage I. Despite this, it must be emphasised that primary DLCL of the ocular adnexa should be regarded with mistrust and that, following radiotherapy, regular patient contact has to be maintained (for example, 6 monthly appointments for the first 2 years).

Various therapeutic regimens were applied in the current series. Patients with stage I disease were treated with surgical excision, radiotherapy, chemotherapy, or a combination of the above. All patterns achieved satisfactory results with various success rates for different lymphoma types. Patients with a lymphomatous disease of stage II or higher had a poorer outcome compared with those with stage I disease, irrespective of the kind of therapeutic regimen applied. Baldini et al noted good responses of stage I lymphomas to radiotherapy, ${ }^{12}$ while we observed a satisfying outcome for all therapeutic regimens, including surgical excision alone in lymphomas of low grade malignancy. It should be noted, however, that more recurrences were observed following surgical excision alone compared with radiotherapy.

Statistical analysis of the lymphoma malignancy category and the stage of disease at manifestation in the ocular adnexa did not prove to be significant $(\mathrm{p}=0.5)$. This can probably be accounted for by the relatively large number of cases of DLCL with stage I disease in comparison with other studies. ${ }^{10}$ However, a significant relation between lymphoma malignancy grade and the prognosis was found $(p=0.03)$. These results are supported by Coupland et $a l,{ }^{10}$ but not by other authors. ${ }^{5}$ On the other hand, the subdivision of the primary OAL into EMZL and "other" lymphoma subtypes did not reveal a significant difference in prognosis $(\mathrm{p}=0.5)$, as reported by White $e t a l^{2}$ and Baldini et $a l^{12}$ These results are, however, contrary to those of Cahill et $a l{ }^{18}$ who found a better prognosis of primary EMZL compared with other lymphoma subtypes.

Immunohistological markers which were demonstrated in this study to have significant prognostic value were $\mathrm{Ki}-67$ antigen and p53 protein expression. The positivity of the tumour cells for $\mathrm{Ki}-67$ antigen and $\mathrm{p} 53$ protein showed a significant correlation with the lymphoma malignancy category, as well as with the final outcome $(p<0.001$ and $p<0.05)$. Similar findings were presented recently in a previous study. ${ }^{10} \mathrm{CD} 5$ (a T cell antigen which can be aberrantly expressed by some $\mathrm{B}$ cell lymphomas) was proposed as another prognostic marker for EMZL in the ocular adnexa as well as in other locations. CD5 positivity should correlate with persistent tumour or recurrent disease. ${ }^{22}$ We could not demonstrate this association in our small number of CD5 positive EMZL.

Although statistically not significant $(p=0.4)$, the current investigation found a difference in the patients' outcome depending on tumour location. The orbital and conjunctival lymphomas seem to have a better prognosis compared with the lymphomas of the lid. Other authors found that the lid lymphomas had a significantly worse prognosis compared with those of the orbita and conjunctiva; the latter having the best prognosis overall. ${ }^{42}$ This point is controversial in the literature as other studies did not find any difference in outcome according to tumour location. ${ }^{1024}$ From our reclassification study of OAL, we can support the findings of other studies that EMZL is the most common lymphoma subtype to occur in these locations and that EMZL, in general, has a favourable prognosis. The stage at diagnosis, the lymphoma malignancy category, as well as $\mathrm{Ki}-67$ antigen and $\mathrm{p} 53$ protein expression have prognostic value with regard to the final outcome in OAL. Complete remission was obtained in approximately $75 \%$ of our patients with a primary EMZL following treatment. Surgical excision, as well as radiotherapy, led to complete remission, nevertheless more local recurrences were observed in those treated by surgical excision alone. Thus, primary EMZL would be treated best with an excisional biopsy, where possible, combined with radiotherapy. Primary DLCL should be treated at least with the identical regimen combined, however, with more intensive follow up investigations. Further studies are required to better understand the pathogenesis of lymphomas, particularly EMZL, in the ocular adnexa in the hope of optimising their treatment.

We thank M Olschewski (Institut für Medizinische Biometrie und Medizinische Informatik, Freiburg, Germany) for the survival analysis.

1 Ellis JH, Banks PM, Campbell RJ, et al. Lymphoid tumors of the ocular adnexa. Clinical correlation with the working formulation classification and immunoperoxidase staining of paraffin sections. Ophthalmology 1985;92:1311-24.

2 White WL, Ferry JA, Harris NL, et al. Ocular adnexal lymphoma. A clinicopathologic study with identification of lymphomas of mucosa-associated lymphoid tissue type Ophthalmology 1995;102:1994-2006.

3 Isaacson P, Wright D. Extranodal lymphoma arising from Isacson P, Wright D. Extranodal lymphoma arising from
mucosa-associated lymphoid tissue. Cancer 1984;53:251524 .

4 Knowles DM, Jakobiec FA, McNally L, et al. Lymphoid hyperplasia and malignant lymphoma occurring in the ocular adnexa (orbit, conjunctiva, and eyelids): a prospective multiparametric analysis of 108 cases during 1977 to 1987 [see comments]. Comment in: Hum Pathol 1991;22: 729-31. Hum Pathol 1990;21:959-73.

5 Vogiatzis K. Lymphoid tumors of the orbit and ocular adnexa: a long-term follow-up. Ann Ophthalmol 1984;16: 1046-55.

6 Gerard-Marchant R, Hamlin I, Lennert K, et al. Classification of non-Hodgkin's lymphomas (letter). Lancet 1974; 2:406-8.

7 Project TN-HsLPC. National Cancer Institute sponsored study of classifications of non-Hodgkin's lymphomas: summary and description of a working formulation for clinical usage. Cancer 1982;49:2112-35.

8 Harris NL, Jaffe ES, Stein H, et al. A revised EuropeanAmerican classification of lymphoid neoplasms: a proposal fincosal from the International Lymphoma Study Group [see comments]. [Review] [296 refs] Comment in. Blood 1994;84: 1359-60; Comment in: Blood 1995;85:857-60; Comment 
in: Blood 1995;85:1972-4; Comment in: Blood 1996;87: 412-3; Comment in: Blood 1996;88:2361-2. Blood 1994; 84:1361-92.

9 Lennert K, Feller A. Histopathology of non-Hodgkin lymphomas (based on the updated Kiel classification). 2nd revised ed. New York: Springer-Verlag, 1992.

10 Coupland SE, Krause L, Delecluse HJ, et al. Lymphoproliferative lesions of the ocular adnexa. Analysis of 112 cases. Ophthalmology 1998;105:1430-41.

11 Liesegang TJ. Ocular adnexal lymphoproliferative lesions. [Review] [54 refs]. Mayo Clinic Proc 1993;68:1003-10.

12 Baldini L, Blini M, Guffanti A, et al. Treatment and prognosis in a series of primary extranodal lymphomas of the ocular adnexa. Ann Oncol 1998;9:779-81.

13 Norton A, Jordan S, Yeomans P. Brief, high temperature heat denaturation (pressure cooking): a simple an effective method of antigen retrieval for routinely processed tissues. 7 Pathol 1994;173:371-9.

14 Cordell JL, Falini B, Erber WN, et al. Immunoenzymatic labeling of monoclonal antibodies using immune complexes of alkaline phosphatase and menoclonal antiplexes of alkaline phosphatase and menoclonal antialkaline phosphatase (APAA

15 Smithers D. Summary of papers delivered at the Conference on Staging in Hodgkin's disease (Ann Arbor). Cancer Res 1971;31:1869-70.

16 Kaplan E, Meier P. Non-parametric evaluation from incomplete observation. $\mathcal{F}$ Am Stat Assoc 1958;53:457-8.
17 Coupland SE, Foss H, Assaf C, et al. T-cell and T/natural killer-cell lymphomas involving ocular and ocular adnexal tissues: a clinicopathologic, immunohistochemical and molecular study of 7 cases. Ophthalmology 1999;106:210920

18 Cahill M, Barnes C, Moriarty P, et al. Ocular adnexal lymphoma-comparison of MALT lymphoma with other histological types. Br f Ophthalmol 1999;83:742-7.

19 Knowles DMI, Jakobiec FA. Orbital lymphoid neoplasms: a clinicopathologic study of 60 patients. Cancer 1980;46: 576-89.

20 Jakobiec FA, McLean I, Font RL. Clinicopathologic characteristics of orbital lymphoid hyperplasia. Ophthalmology 1979;86:948-66.

21 Petrella T, Bron A, Foulet A, et al. Report of a primary lymphoma of the conjunctiva: A lymphoma of MALT origin? Pathol Res Pract 1991;187:78-84.

22 Ferry J, Yang W, Zukerberg L, et al. CD5+ extranodal marginal zone B-cell (MALT) lymphoma. A low grade neoplasm with the propensity for bone marrow involvement and relapse. Am f Clin Pathol 1996;105:31-7.

23 Jakobiec FA, Knowles DM. An overview of ocular adnexal lymphoid tumors. Tran Am Ophthalmol Soc 1989;87:42044 .

24 Medeiros LJ, Harmon DC, Linggood RM, et al. Immunohistologic features predict clinical behavior of orbital and conjunctival lymphoid infiltrates. Blood 1989;74:2121-9. 